\title{
Formação ética para a cidadania: reorganizando contingências na interação professor-aluno
}

\author{
Juliana Ferreira da Rocha \\ Kester Carrara
}

\section{Resumo}

Este estudo baseou-se no pressuposto de que os professores constituem importantes modelos e funcionam como ambiente social relevante para a emissão de comportamentos de seus alunos. Nessa perspectiva, avaliou o efeito de um programa instrucional desenvolvido com duas professoras do ensino fundamental sobre a aquisição, por seus alunos, de repertórios fundamentais para o desenvolvimento de relações interpessoais condizentes com o exercício da cidadania. O programa consistiu na apresentação de comportamentos socialmente habilidosos como elogiar, dar feedback positivo e pedir mudança de comportamento, que visavam instruir as professoras à aplicação e habilidades requeridas em áreas do funcionamento socioafetivo coerentes com comportamentos pró-éticos e pró-sociais de seus alunos. Os efeitos do procedimento de capacitação foram verificados a partir das avaliações de desempenho dos alunos antes e depois da etapa de intervenção. Os resultados obtidos sugerem que a intervenção com as professoras foi efetiva no desenvolvimento de repertório de comportamentos pró-éticos das crianças.

Palavras-chave: Cidadania, políticas públicas, habilidades sociais.

\section{Ethical development to the citizenship: reorganizing contingencies in interaction teacher-student}

\begin{abstract}
In this work we argue that teachers are important and relevant standards that may influence on their students behavior. In this sense, we evaluate a teaching program, developed with Elementary school teachers. We observe the purchase by students of important fundamental repertoire to the development of interpersonal relation according to the citizenship practice. The program was made by a presenting skilful social behavior such as, praising, giving positive feedback, asking a behavior's change that aimed to teach teachers how to apply the desired skills on affective social work., according to pro-ethical and pro-social behaviou with their students. The students' procedures were verified before and after the intervention's stage. The results suggest that the interaction with teachers were effective on the childen's pro-ethics repertoire.
\end{abstract}

Keywords: Citizenship, public policies, social skills.

\section{Formación ética para la ciudadanía: reorganizando contingencias en la interacción profesor-alumno}

\begin{abstract}
Resumen
Este estudio se basa en el supuesto de que los profesores constituyen importantes modelos y funcionan como ambiente social relevante para la emisión de comportamientos de sus alumnos. Bajo esta perspectiva, se evaluó el efecto de un programa instructivo desarrollado con dos profesoras de enseñanza básica sobre la adquisición, por parte de sus alumnos, de repertorios fundamentales para el desarrollo de relaciones interpersonales coherentes con el ejercicio de ciudadanía. El programa consistió en la presentación de comportamientos socialmente habilidosos como elogiar, dar feedback positivo y pedir cambio de comportamiento, que buscaban instruir las profesoras para la aplicación de habilidades requeridas en áreas de funcionamiento socio-afectivo coherentes con comportamientos pro-éticos y pro-sociales de sus alumnos. Los efectos del procedimiento de capacitación se verificaron a partir de las evaluaciones de rendimiento de los alumnos antes y después de la etapa de intervención. Los resultados obtenidos sugieren que la intervención con las profesoras fue efectiva en el desarrollo de repertorio de comportamientos pro-éticos de los niños.
\end{abstract}

Palabras Clave: Ciudadanía, políticas públicas, habilidades sociales. 


\section{Introdução}

A conquista da cidadania constitui-se na consolidação da democracia e na busca de igualdade e justiça nas relações sociais, mediante uma participação ativa nas práticas culturais vigentes. Contudo, não se pode restringir a cidadania apenas ao exercício dos direitos registrados na Declaração Universal dos Direitos Humanos (DUDH) ou de documentos com finalidade similar. O termo "cidadania" deve abranger aspectos políticos e filosóficos de uma sociedade, desvinculando-se dos conceitos de concessão e manipulação e sugerindo a construção de competências e habilidades de efetiva participação em práticas culturais presentes no contexto social. Nesse sentido, a participação dos indivíduos na organização e funcionamento da sociedade depende das características de seu repertório pró-ético e pró-social. As denominações "comportamentos pró-éticos" e "comportamentos pró-sociais" remetem a comportamentos preliminares que funcionam como pré-requisitos e são compatíveis com o exercício de interações sociais cooperativas, construtivas e dirigidas à busca da equidade e justiça social.

O conceito de cidadania é caracterizado de acordo com a política, economia e cultura de uma civilização, estando sujeito a transformações vinculadas a essas dimensões. Para caracterizar uma sociedade, faz-se necessário conhecer as peculiaridades de suas práticas culturais e o momento histórico vigente, visto que, conforme Bobbio (1992), "o que parece fundamental numa época histórica e numa determinada civilização não é fundamental em outras épocas e em outras culturas" (p.19). Essa caracterização e esclarecimento da dinâmica das práticas culturais é imprescindível para a viabilização de mudanças no contexto das interações indivíduo-sociedade, o que constitui foco central de análise do desenvolvimento individual e das práticas culturais. Para Carrara e cols. (2004), "é nas interações sociais que os indivíduos organizam a sociedade e, consequentemente, estabelecem os padrões culturais que dão sentido e significado ao contexto coletivo" (p.15).

Nesse contexto, para que haja uma interação eticamente bem qualificada, as pessoas devem ser capazes de compreender os sentimentos uns dos outros e de demonstrar tal compreensão de maneira verbal ou não verbal sob uma perspectiva empática (Falcone, 1998). Os indivíduos que desenvolvem tal competência têm sido caracterizados como socialmente habilidosos por distintas mediações teóricas em Psicologia. Na visão da Análise do Comportamento, "saber comportar-se de forma socialmente habilidosa possivelmente contribui para a aquisição de comportamentos pró-éticos e pró-sociais" (Carrara e cols., 2004, p.11) e, provavelmente, contribui para a identificação, constituição e consolidação da cidadania.

A construção da cidadania pressupõe a instrumentalização dos indivíduos para a participação motivada e competente na organização e funcionamento da vida pública. Essa participação deve estar voltada para o "bem da cultura", o que implica ações que preservem a cultura e evitem práticas para ela deletérias e até letais, "como a superpopulação, a devastação do meio-ambiente, a poluição e a possibilidade de holocausto nuclear" (Skinner, 1971).

Por outro lado, algumas práticas culturais constituem-se em graves problemas para a sobrevivência das culturas humanas. Segundo Del Prette e Del Prette (2001a),

(...) o avanço do neoliberalismo, com a exploração incontrolada dos recursos da Terra, criou problemas de difícil solução e pode representar uma ameaça à vida em muitos lugares em prazo não muito longo. Dentre os maiores desafios estão a proteção ambiental, a distribuição de alimentos a todos os povos, o destino do lixo, em especial os não degradáveis, a democratização do acesso ao conhecimento e a tecnologia e o controle de endemias e epidemias. Tais problemas não possuem soluções exclusivamente técnico-científicas ou econômicas e políticas: requerem novos padrões relacionais entre nações, entre grupos e entre pessoas (p.70).

Embora o avanço do neoliberalismo tenha contribuído para a intensificação do consumismo, ao afirmar noções e valores individualistas calcados no ter em detrimento do ser, "um novo paradigma emerge, ainda que timidamente, privilegiando as relações e a qualidade de vida como fontes de realização pessoal" (Del Prette \& Del Prette, 2001a, p.70). Essa mudança de paradigma é proporcionada a partir da construção da cidadania, na qual o indivíduo sai da condição passiva e passa à ativa, exercendo contracontrole sobre as instituições detentoras do poder vigente.

Skinner descreve outros dois tipos de bens, os bens pessoais e os bens dos outros. Segundo interpretam Dittrich e Abib (2004), bens pessoais são reforçadores positivos em relação ao comportamento da pessoa que os produz, enquanto que bens dos outros são aqueles que, ainda que produzidos por certo indivíduo, resultam em reforçamento positivo para o comportamento de outras pessoas que não o próprio indivíduo. A junção dos bens pessoais e dos bens dos outros com o bem da cultura fortalece projetos coletivos. "Ao participar de uma relação social o indivíduo se comporta visando dois bens, o seu e o de outros" (Abib, 2001, p. 109). Ou seja, para o autor, quando o indivíduo se comporta visando ao bem de outros, objetiva também, intencionalmente ou não, seu próprio bem. Retomando Skinner: “(...) o ambiente social em parte é o resultado daqueles procedimentos do grupo que geram o comportamento ético e a extensão desses procedimentos aos usos e aos costumes" (Skinner, 1953/2000, p. 392).

A cidadania, nesse contexto, remete-nos à articulação entre as múltiplas aspirações individuais e o interesse coletivo. "(...) a noção de cidadania se articula, portanto, à de construção e reconstrução da identidade pessoal/social, mediando, por essa via, a emergência de ações coletivas que buscam uma reparação ou um equilíbrio nas relações entre categorias sociais" (Del Prette \& Del Prette, 2001b, p. 75).

Nesse contexto, o treino de habilidades sociais possui fundamental importância na superação do individualismo em favor da coletividade. Tendo desenvolvido comportamen- 
to socialmente habilidoso, o indivíduo emitirá uma série de respostas apropriadas e/ou requeridas e aprovadas pela comunidade, o que facilitará o seu engajamento em grupos sociais. É evidente que resta aí a discussão ética das prescrições: a quem serve ou a quem interessam os comportamentos emitidos? Eles resultam, ainda que em longo prazo, em benefício para a maioria das pessoas? Na hipótese positiva, isto se dará sem prejuízo de populações minoritárias ou de membros individuais do grupo?

Pensar em práticas culturais que favoreçam o bem da cultura não se restringe apenas a um planejamento cultural para evitar práticas prejudiciais, mas também ao reforçamento de novas práticas que são favoráveis aos indivíduos e às culturas. "É necessário descobrir, inventar e fortalecer práticas que promovam a sobrevivência dos indivíduos e das culturas" (Abib, 2001, p. 110).

Conforme Abib (2001), o conceito de sobrevivência não deve estar atrelado à noção de práticas competitivas entre culturas ou entre pessoas e grupos no interior de culturas, sugerindo compromisso com um darwinismo social, no qual o comportamento agressivo é exaltado. $O$ autor ressalta que "práticas de sobrevivência cultural referem-se, então, a práticas que contribuem para construir uma cultura mais pacífica, e os que se engajam nessas práticas visam o pacifismo" (p. 111). Isso significa promover cooperação, solidariedade e mútuo apoio.

Por outro lado, é notório que a passividade das pessoas frente à construção da cidadania pode conduzir ao estranhamento e à alienação. Para Abib (2001):

(...) isso significa dizer que, como na maioria das vezes, o comportamento das pessoas, em vez de ser modelado por contingências, é governado por regras; elas não têm experiência direta nem com os comportamentos, nem com as situações, nem com as consequências de suas ações. As pessoas desenvolvem então uma relação de estranhamento como o seu mundo, um mundo onde a experiência com a produção pessoal de bens culturais é substituída meramente por seu consumo. (...) Ou seja, as sociedades desenvolvidas ou maduras estão formando pessoas alienadas de seu mundo e incapazes ao mesmo tempo de compreender outros mundos. (p.112).

Com a consolidação democrática no país, o enfoque da escola pública nos conteúdos passou a ceder espaço para uma ênfase na formação ético-moral do alunado, tema transversal que objetiva a formação de cidadãos participantes nas decisões políticas e na difusão do conhecimento dentro de um contexto cooperativo. Essa iniciativa, apoiada nos planos políticos e em vários programas de ação dos governos municipais, estaduais e federal nos últimos anos, atualmente tende à ampliação e estabelecimento de formação acadêmica mais completa, competente e politicamente correta em todos os níveis de ensino. Uma exigência cada vez mais observável, em tempos recentes, é que o processo educacional vise, para além da compatibilidade entre os conteúdos ensinados e as demandas sociais, à formação ética geral do cidadão.

A preocupação com a formação ético-moral destinada à capacitação da população para consolidar os melhores valores sociais compatíveis com a cidadania é visível em documentos orientadores, como, por exemplo: Lei de Diretrizes e Bases (LDB), Parâmetros Curriculares Nacionais (PCN) e Referencial Curricular Nacional para Educação Infantil (RCNEI).

Para Del Prette e Del Prette (2001b), a escola, em particular, é um espaço privilegiado, onde se dá um conjunto de interações sociais que se pretendem educativas. Esse espaço possibilita a emissão de comportamentos pró-éticos e pró-sociais, visto que a criança depende da existência de condições favoráveis em seu meio que a levem a isso (Robinson, 2001). Dessa forma, intervir no meio, disponibilizando consequências favoráveis, amplia a probabilidade de que comportamentos socialmente e/ou eticamente elegíveis ocorram. Como consta na legislação orientadora:

(...) nas interações sociais se dá a ampliação dos laços afetivos que as crianças podem estabelecer com as outras crianças e com os adultos, contribuindo para que o reconhecimento do outro e a constatação das diferenças entre as pessoas sejam valorizadas e aproveitadas para o enriquecimento de si próprias (Brasil, 1998, p. 11).

Sob a perspectiva ético-moral, os comportamentos próéticos e pró-sociais funcionam como repertório básico que a criança pode e deve aprender e utilizar, desde logo, no convívio com seus pares mais próximos, como os adultos da família, os colegas da própria escola e em quaisquer outras situações de interação, de caráter lúdico ou socializante. O desenvolvimento dessa competência permite a essas crianças agirem como disseminadores, para outras turmas, de habilidades educacionais diversas para assegurar o desenvolvimento da cidadania.

Skinner (1953/2000) sugere que a instituição educacional deve não só divulgar o saber, mas ensinar o estudante a pensar, a observar, a reunir materiais relevantes, a organizá-los e a propor soluções para problemas. Del Prette e Del Prette (2005a) relatam a importância de se priorizar o desenvolvimento de valores e comportamentos pró-sociais na escola, com destaque para empatia, solução de problemas interpessoais e controle da impulsividade e da raiva. Os mesmos autores destacam que as habilidades sociais são requisitos para os alunos participarem mais ativamente nas interações sociais educativas em sala de aula, assegurando a promoção de interações mais gratificantes e a participação na sociedade.

O processo educacional direcionado para o desenvolvimento de competências desejáveis no aluno, visando ao preparo para atividades produtivas, assegura também o desenvolvimento de capacidades condizentes com o exercício da cidadania. Ao promover a ampliação de habilidades sociais, a escola estará garantindo a sua função de ser res- 
ponsável, em grande parte, pelo desenvolvimento de ações que visem à formação de indivíduos participativos, reflexivos e críticos da realidade e, consequentemente, fundamentados para transformá-la. Nesse sentido, a escola possibilitará condições para que seus alunos possam superar a condição de receptáculos passivos para atuarem como indivíduos ativos no meio social.

A formação ético-moral do cidadão não se constitui repentinamente numa determinada fase do ciclo vital, nem se dá mediante simples exposição às regras sobre o comportamento ético ou a documentos formais sancionados pelas agências de controle social. A formação para a cidadania se consolida na medida em que, desde as primeiras interações sociais, as condições essenciais de formação do caráter estejam presentes e se organizem contingências para a sua instalação e manutenção. Seguramente, é na infância e na adolescência que podem ser assegurados os pré-requisitos essenciais para tal,

(...) embora a compreensão mais elaborada das razões sócio-políticas de direitos e deveres do cidadão deva aparecer mais tarde, no processo de desenvolvimento; por exemplo, no contexto da convivência familiar, no ensino formal de adolescentes e adultos e na universidade, entende-se, em contrapartida, que uma parte significativa de tal formação deve ser oferecida já a partir da educação infantil, fortalecendo-se significativamente durante 0 ensino fundamental, sempre, naturalmente, mediante as adequações necessárias à faixa etária respectiva (Carrara e cols., 2004, p. 8).

Dessa maneira, parte-se da concepção de que a criança em idade escolar encontra-se numa das fases mais decisivas do processo de desenvolvimento de seus valores socioculturais, concebendo a escola como um ambiente destinado a promover exatamente a fundamentação desse processo. De acordo com Carrara e cols. (2004), as crianças cuja faixa etária corresponde à primeira série do ensino fundamental estão num dos momentos mais cruciais de estabelecimento e consolidação dos padrões de interação social, de maneira que as situações de interação vivenciadas na infância permitirão ou dificultarão o desenvolvimento de habilidades interpessoais fundamentais para a vida adulta.

A Psicologia (e as ciências do comportamento, de modo geral) vem lentamente fazendo avançar suas investigações para além dos tradicionais casos clínicos, para além da seleção e capacitação de pessoal, para além das consultorias educacionais; está, agora, mais que em vários outros momentos de sua consolidação científica, ampliando pesquisas concebidas para aprimorar teoria e estratégias que possam contribuir para a construção de uma sociedade igualitária e justa.

Psicólogos detêm e dominam informações, estratégias de intervenção, técnicas, métodos e conhecimento substantivo acerca da interação humana. Tal conhecimento deve superar os limites do bem-estar individual, ao ser compartilhado com o interesse coletivo em direção ao bem da cultura e ao exercício da cidadania. Contudo, não cabe à própria Psicologia definir todas as estratégias de ação necessárias ou possíveis para o tratamento de questões como o delineamento cultural e os princípios ético-morais. Trata-se de uma tarefa conjunta da qual são tributárias outras ações concretas nas áreas de economia, seguridade social e saúde, por exemplo. Retomando Carrara: "a conquista da cidadania deve passar por um processo construído, projetado com a utilização ótima do conhecimento disponível e com a integral participação de todos quantos estejam conscientes de sua importância" (Carrara, 1995, p.7).

Admitindo a impossibilidade de uma ciência neutra, o compromisso social desta pode ser diferente em cada cultura, em função dos valores eleitos num determinado momento histórico. Nesse sentido, não são ignoradas as dificuldades a serem encontradas no estabelecimento de uma visão consensual acerca da formação de sujeitos éticos/ morais. Os princípios éticos/morais só adquirem significado prático quando o caráter abstrato e geral que possuem é confrontado com o conteúdo concreto da realidade vivida (Oliveira, 2001). Desse modo, para designar os valores a serem agregados aos comportamentos pró-sociais ou pró-éticos, o cientista deve participar da discussão juntamente com a parcela populacional envolvida na questão.

Neste momento, faz-se necessário ampliar esclarecimentos sobre o significado das expressões "pró-ético" e "pró-social". Essas expressões implicam uma preparação gradativa para uma inserção social adulta adequada sob a perspectiva ético-moral por meio da apropriação de repertórios comportamentais específicos, acessíveis às crianças, voltados ao desenvolvimento da cidadania. Nesse sentido, constituem repertórios comportamentais que funcionam como pré-requisito para o exercício integral da cidadania na vida adulta, e o momento mais apropriado de sua instalação e consolidação, no contexto do processo de desenvolvimento humano, parece ser a infância.

É nesse contexto da literatura e a partir da mediação teórica da análise comportamental que o presente estudo elegeu como seu objetivo geral avaliar os efeitos de um programa instrucional desenvolvido com professores do ensino fundamental sobre a aquisição, por seus alunos, de repertórios socialmente habilidosos nas relações interpessoais condizentes com o exercício da cidadania.

A idéia de avaliar o efeito de um programa instrucional junto a professores de uma EMEF surgiu durante a realização de um projeto mais abrangente intitulado "Ensino fundamental, aprendizagem e desenvolvimento: um aporte da Psicologia à construção da cidadania" (projeto de pesquisa concluído em 2006 com apoio da Fapesp, no contexto do Edital de Ensino Público - processo número 2004/141570 ), o qual teve como principal objetivo avaliar o efeito de práticas educacionais que favorecessem o desenvolvimento da cidadania em escolares do ensino fundamental, através da consolidação de repertórios de comportamentos próéticos diversos e, particularmente, os que incluíam respeito à diversidade (Carrara e cols., 2004, p. 17). 
Contextualizado sob abordagem compatível com o projeto recém-mencionado, o presente estudo teve como participantes-alvo alunos e professores que contribuíram para a promoção de comportamentos pró-éticos e pró-sociais em alunos de primeira série. Os objetivos específicos da investigação foram: a) Identificar, no repertório atual das crianças da série estudada, a existência de comportamentos voltados ao desenvolvimento da cidadania; b) A partir do repertório existente, fornecer instruções para o professor com vistas à aplicação de estratégias e recursos para instalação e consolidação de habilidades requeridas em áreas do funcionamento socioafetivo coerentes com comportamentos pró-éticos e pró-sociais em sala de aula e participar de momentos da aula fornecendo modelos ao professor sobre como mediar as relações de acordo com o repertório em particular a ser instalado; c) Avaliar os efeitos das atividades em sala de aula mediadas pelo professor a partir da comparação dos resultados do desempenho dos alunos após a intervenção com os resultados obtidos antes da intervenção.

\section{Método}

\section{Participantes}

Foram selecionadas para este estudo duas professoras de duas classes de primeira série do ensino fundamental e 24 alunos, escolhidos aleatoriamente, das respectivas professoras. Os alunos estavam na faixa etária dos seis aos oito anos completos no período da pesquisa. Os participantes foram separados em alunos e professora da sala 1 e alunos e professora da sala 2 , como é apresentado na tabela 1.

Tabela 1. Caracterização dos participantes

\begin{tabular}{cccc}
\hline & \multicolumn{2}{c}{ Participantes } & Total \\
\hline $\begin{array}{c}\text { Professora 1 } \\
\text { Sala 1 }\end{array}$ & 6 meninas & 6 meninos & 12 \\
$\begin{array}{c}\text { Professora 2 } \\
\text { Sala 2 }\end{array}$ & 6 meninas & 6 meninos & 12 \\
\hline
\end{tabular}

\section{Procedimento de coleta de dados e instrumentos utilizados}

Os dados foram coletados na própria EMEF, durante o horário de aula. As professoras autorizaram a pesquisadora a retirar os alunos (um por vez) da sala para a aplicação do instrumento. A etapa de intervenção também ocorreu na própria escola, semanalmente, em horários previamente acordados entre as professoras e a pesquisadora primeira autora.
As habilidades sociais das crianças foram investigadas com a aplicação do Inventário Multimídia de Habilidades Sociais para Crianças (IMHSC - Del Prette \& Del Prette, 2005b). Esse instrumento contempla a autoavaliação das crianças sobre os comportamentos socialmente habilidosos para o sucesso escolar e o ajustamento social.

O IMHSC é um instrumento de autorrelato informatizado em CD-ROM, o qual apresenta, sob forma de trecho de vídeo, 21 situações e reações de interações sociais de crianças das séries iniciais do ensino fundamental com outras crianças ou com adultos. Em cada situação, há três alternativas de reação apresentadas pela personagem principal: reação habilidosa (demonstra assertividade, empatia, expressão de sentimentos positivos ou negativos de forma apropriada, civilidade etc.), reação não habilidosa passiva (demonstra esquiva ou fuga ao invés de enfrentamento da situação) e a reação não habilidosa ativa (demonstra agressividade, ironia, autoritarismo etc.). As situações que aparecem no inventário ocorrem principalmente em ambiente escolar, dada sua importância para a socialização e o ajustamento da criança nessa fase do seu desenvolvimento.

\section{Fase de avaliação}

Ao ser iniciada a sessão de avaliação, estabelecia-se, primeiramente, rapport com a criança, deixando-a à vontade, explicando o motivo da atividade, reduzindo sua ansiedade natural devida à nova condição e criando motivação para o teste. Feito isso, explicava-se à criança que ela iria assistir a um filme em que outras crianças atuavam e esse filme mostrava como elas interagiam com outras pessoas. Então, a criança participante deveria observar o comportamento da personagem principal e, em seguida, escolher o comportamento que ela também emitiria (tal como a personagem agiu na situação A, B ou C). Enfatizava-se que não existiam respostas certas ou erradas, solicitava-se atenção e sinceridade da criança ao responder e avisava-se que permaneceria no local para ajudá-la, caso necessário. A aplicadora iniciava o filme, a criança assistia à situação e as possíveis reações; em seguida, clicava com o mouse na reação escolhida e então dava início à situação seguinte, até chegar ao final das 21 situações.

De acordo com Del Prette e Del Prette (2005b), "as situações retratadas no IMHSC-Del-Prette permitem uma amostragem de habilidades requeridas em áreas do funcionamento sócio-afetivo". O desenvolvimento dessas habilidades propicia o desenvolvimento de comportamento socialmente habilidoso (incluindo respeito mútuo, cooperação, sinceridade e outros atributos positivos) e, consequentemente, favorece a qualidade das relações da criança com colegas e professores e o seu desempenho acadêmico. $\mathrm{O}$ comportamento habilidoso está diretamente relacionado com os "comportamentos pró-éticos" e "comportamentos pró-sociais" visto que propiciam a instalação e/ou fortale- 
cimento de um repertório eticamente comprometido com a justiça social.

\section{Fase de intervenção}

Após a coleta inicial de dados, foi realizada a intervenção com a professora e alunos da sala 1.

Foram realizadas cinco sessões com a participação da professora da sala 1 e a pesquisadora primeira autora. Os encontros foram realizados na própria escola, às segundas-feiras, antes do início da aula, com 50 minutos de duração cada. O primeiro encontro teve como objetivo a apresentação do projeto e a definição de comportamentos pró-éticos e pró-sociais à professora, bem como a dessensibilização da professora e dos alunos em relação à participação da pesquisadora na sala de aula. Nos demais encontros, foram discutidos, respectivamente, os seguintes temas: Expressar sentimentos positivos, elogiar, dar e receber feedback positivo, agradecer; Expressar desagrado e pedir mudança de comportamento; Habilidades de analisar problemas e tomar decisões; Solução de problemas interpessoais na sala de aula. Os temas foram definidos a partir da literatura e da análise das avaliações com os alunos.

Na primeira parte de cada sessão, a pesquisadora investigava a tarefa de casa e os acontecimentos da semana relacionados à interação entre professor e aluno. $\mathrm{Na}$ sequência, eram trabalhadas habilidades para que a professora pudesse estimular o desenvolvimento dos alunos, com prioridade para comportamentos pró-éticos e pró-sociais. A pesquisadora discutia com a participante cada uma das habilidades considerando o que a mesma já sabia e já fazia, bem como as dificuldades que encontrava. Na discussão dessas habilidades, destacou-se a importância para promover o desenvolvimento pró-ético e pró-social dos alunos, bem como a transformação ou eventual supressão de comportamentos incompatíveis com aqueles a serem instalados.

O passo seguinte da sessão de capacitação era a exposição teórica dialogada acerca do tema específico, momento em que novamente foram identificadas dificuldades e discutidas possibilidades de resolução de problemas, sob a mediação teórica da Análise do Comportamento. Foram fornecidos conceitos, modelos de atuação, experiências práticas e vivências.

As sessões eram finalizadas com a avaliação dos procedimentos e, a partir do segundo encontro, com a solicitação de tarefa para casa, envolvendo o tema abordado na sessão; era recomendada à professora a execução dos comportamentos treinados junto a seus alunos como tarefa para todos os dias da semana.

\section{Procedimentos de análise e tratamento dos dados}

As respostas dos participantes foram classificadas de acordo com as reações: habilidosa, não habilidosa passiva e não habilidosa ativa, e tratadas estatisticamente (SPSS, versão 14.0) a fim de verificar diferenças entre as avaliações pré e pós- intervenção.

Foi adotado um delineamento de linha de base múltipla (Cozby, 2006), típico de várias pesquisas apoiadas na Análise do Comportamento, o qual contempla intervenção em momentos diferentes para os participantes e verifica se a mudança no desempenho ocorre para todos, visando excluir interpretações baseadas no tempo, na história de aprendizagem e visando ampliar a consistência para atribuição da mudança à variável independente, representada pelo contexto da intervenção.

Todos os 24 participantes passaram pela primeira avaliação (pré-teste) e, em seguida, os 12 alunos da professora da sala 1 passaram por intervenção. Ao final da intervenção com a professora da sala 1 , todos os participantes $(n=24)$ foram reavaliados, constituindo-se tal sessão em avaliação pós-intervenção para a sala 1 e pré-teste 2 para a sala 2. Ao concluir a análise dos dados da segunda avaliação, a pesquisadora iniciou a intervenção com a professora da sala 2, abordando os mesmos temas e seguindo a mesma estrutura dos encontros realizados com a professora anterior. Terminada essa etapa, os alunos da sala 2 $(n=12)$ foram reavaliados, seguindo o mesmo procedimento anterior, caracterizando a avaliação pós-intervenção desse grupo.

\section{Resultados}

A avaliação pré-intervenção possibilitou identificar, no repertório das crianças da série estudada, a existência de comportamentos voltados ao desenvolvimento da cidadania (reações habilidosas) e qual repertório deveria ser ensinado (reações ativas) ou aperfeiçoado (reações passivas) com a intervenção, tendo em vista a instalação de habilidades requeridas em áreas do funcionamento socioafetivo coerentes com comportamentos pró-éticos e pró-sociais. A avaliação pós-intervenção permitiu verificar o efeito do programa instrucional e das atividades em sala de aula mediadas pela professora.

Em situações como fazer perguntas à professora, solicitar mudança de comportamento ao outro, propor novas brincadeiras, os alunos agiam de maneira passiva ou agressiva. Diante dessas situações, as professoras relataram que não sabiam o que fazer, ora respondiam de maneira agressiva, gritando, mandando os alunos para a diretoria ou os ignoravam e assim não apresentavam aos alunos outras maneiras de agir.

Após a etapa de intervenção, as professoras passaram a mediar situações de conflito entre os alunos solicitando mudança de comportamento e ensinando-os a solicitar. Perguntavam diversas vezes se eles entenderam o que ela havia explicado, apresentavam modelos de perguntas que eles poderiam fazer para esclarecer dúvidas; diante de queixas sobre brigas, perguntavam aos alunos o que os desagradou e os orientavam a dizer ao colega, sem gritar ou agredir e apontavam novas maneiras de agir. 
Tabela 2. Avaliação de normalidade da amostra

\begin{tabular}{cccccc}
\hline \multicolumn{1}{c}{ Reações } & N & M & DP & Kolmogorov-Smirnov Z & p \\
\hline Socialmente habilidosa & 24 & 0,44 & 0,19 & 0,85 & 0,45 \\
Não habilidosa passiva & 24 & 0,30 & 0,10 & 0,72 & 0,66 \\
Não habilidosa ativa & 24 & 0,25 & 0,18 & 0,67 & 0,74 \\
\hline
\end{tabular}

$\mathrm{N}=$ número de participantes $\mathrm{M}=$ média $\mathrm{DP}=$ desvio padrão

Tabela 3. Avaliação pré-teste das salas 1 e 2 como amostras independentes

\begin{tabular}{|c|c|c|c|c|c|c|}
\hline \multirow{2}{*}{ Reações } & \multicolumn{2}{|c|}{ Sala 1} & \multicolumn{2}{|c|}{ Sala 2} & \multirow{2}{*}{$\mathrm{t}$} & \multirow{2}{*}{$\mathrm{p}$} \\
\hline & M & DP & M & DP & & \\
\hline Socialmente habilidosa & 0,34 & 0,16 & 0,53 & 0,18 & $-2,59$ & 0,01 \\
\hline Não habilidosa passiva & 0,30 & 0,09 & 0,30 & 0,10 & 0,06 & 0,95 \\
\hline Não habilidosa ativa & 0,35 & 0,19 & 0,16 & 0,13 & 2,75 & 0,01 \\
\hline
\end{tabular}

$\mathrm{M}=$ média $\quad \mathrm{DP}=$ desvio padrão

Tabela 4. Média e desvio padrão da primeira avaliação e da avaliação pósintervenção do grupo todo

\begin{tabular}{|c|c|c|c|c|c|c|c|}
\hline \multirow[b]{2}{*}{ Reações } & \multirow[b]{2}{*}{$\mathrm{N}$} & \multicolumn{2}{|c|}{ Pré-Teste } & \multicolumn{2}{|c|}{ Pós-Teste } & \multirow[b]{2}{*}{$\mathrm{t}$} & \multirow[b]{2}{*}{$\mathrm{p}$} \\
\hline & & M & $\mathrm{DP}$ & M & $\mathrm{DP}$ & & \\
\hline Socialmente habilidosa & 24 & 0,44 & 0,19 & 0,65 & 0,16 & $-5,30$ & 0,00 \\
\hline Não habilidosa passiva & 24 & 0,30 & 0,10 & 0,25 & 0,12 & 1,62 & 0,11 \\
\hline Não habilidosa ativa & 24 & 0,25 & 0,18 & 0,09 & 0,10 & 5,04 & 0,00 \\
\hline
\end{tabular}

Tais resultados puderam ser observados a partir do relato das professoras e da aplicação do IMHSC-Del-Prette nos alunos participantes.

A amostra foi submetida à avaliação de normalidade, a qual não apresentou diferença estatística, como pode ser observado na tabela 2.

Como não houve diferença estatística ao comparar com curva normal, foi aplicado o teste paramétrico nas análises. Foram avaliados os dados das salas 1 e 2 , com o teste t para amostras independentes e o resultado indicou que as salas são diferentes em relação à linha de base, garantindo que as salas podem ser tratadas como distintas, sugerindo comparações intra-grupo (sala $1 \mathrm{com}$ sala 1 e sala $2 \mathrm{com}$ sala 2, antes e pós-intervenção), como pode ser observado na tabela 3.

Com o propósito de avaliar se houve diferença significativa entre a primeira avaliação e a avaliação pós-intervenção das salas 1 e 2 ( $n=24)$, foi realizado um teste t pareado para o grupo como um todo. O resultado do teste $t$ indicou significância para as reações habilidosas e reações ativas (tabela 4). Portanto, a intervenção foi efetiva, propiciou meIhora nas reações habilidosas e redução nas reações não habilidosas ativas, como pode ser observado na tabela 4 .

Como as duas salas de aula apresentaram diferente desempenho na avaliação inicial do IMHSC, o mesmo teste estatístico foi realizado para os grupos separados, salas 1 e 2 . 
Tabela 5. Média e desvio padrão da avaliação pré e pós-teste da sala 1 e sala 2

\begin{tabular}{|c|c|c|c|c|c|c|c|c|c|c|c|c|}
\hline \multirow[b]{2}{*}{ Reações } & \multicolumn{2}{|c|}{$\begin{array}{c}\text { Sala } 1 \\
\text { Pré-Teste }\end{array}$} & \multicolumn{2}{|c|}{$\begin{array}{c}\text { Sala 1 } \\
\text { Pós-Teste }\end{array}$} & \multirow[b]{2}{*}{$\mathrm{t}$} & \multirow[b]{2}{*}{$\mathrm{p}$} & \multicolumn{2}{|c|}{$\begin{array}{c}\text { Sala } 2 \\
\text { Pré-Teste }\end{array}$} & \multicolumn{2}{|c|}{$\begin{array}{c}\text { Sala } 2 \\
\text { Pós-Teste }\end{array}$} & \multirow[b]{2}{*}{$\mathrm{t}$} & \multirow[b]{2}{*}{$\mathrm{p}$} \\
\hline & M & DP & M & DP & & & M & DP & M & DP & & \\
\hline $\begin{array}{l}\text { Socialmente } \\
\text { habilidosa }\end{array}$ & 0,34 & 0,16 & 0,60 & 0,18 & $-4,57$ & 0,00 & 0,58 & 0,13 & 0,69 & 0,13 & $-3,06$ & 0,01 \\
\hline $\begin{array}{l}\text { Não } \\
\text { habilidosa } \\
\text { passiva }\end{array}$ & 0,30 & 0,96 & 0,25 & 0,14 & 1,24 & 0,24 & 0,30 & 0,09 & 0,26 & 0,11 & 1,32 & 0,21 \\
\hline $\begin{array}{l}\text { Não } \\
\text { habilidosa } \\
\text { ativa }\end{array}$ & 0,35 & 0,19 & 0,14 & 0,97 & 3,70 & 0,00 & 0,11 & 0,13 & 0,04 & 0,07 & 2,77 & 0,01 \\
\hline
\end{tabular}

Tabela 6. Teste t entre as duas medidas de pré-avaliação da sala 2

\begin{tabular}{|c|c|c|c|c|c|c|}
\hline \multirow[b]{2}{*}{ Reações } & \multicolumn{2}{|c|}{ Pré-Teste 1} & \multicolumn{2}{|c|}{ Pré-Teste 2} & \multirow[b]{2}{*}{$\mathrm{t}$} & \multirow[b]{2}{*}{$\mathrm{p}$} \\
\hline & $\mathrm{M}$ & $\mathrm{DP}$ & $\mathrm{M}$ & $\mathrm{DP}$ & & \\
\hline Socialmente habilidosa & 0,05 & 0,18 & 0,58 & 0,13 & $-0,88$ & 0,39 \\
\hline Não habilidosa passiva & 0,30 & 0,10 & 0,30 & 0,09 & $-0,16$ & 0,87 \\
\hline Não habilidosa ativa & 0,16 & 0,13 & 0,11 & 0,13 & 1,07 & 0,30 \\
\hline
\end{tabular}

$\mathrm{M}=$ média $\quad \mathrm{DP}=$ desvio padrão

A aplicação do teste t para a sala 1 e para sala 2, separadamente, indicou significância para reações habilidosas e não habilidosas ativas; houve aumento da primeira reação e redução da segunda, como pode ser observado na tabela 5.

A fim de avaliar a eficácia do delineamento adotado, foi aplicado teste t entre as duas medidas de pré-avaliação da sala 2 e não houve diferença significativa (tabela 6).

Desse modo, os dados sugerem que o delineamento adotado, linha de base múltipla, permitiu verificar que as mudanças nas reações dos alunos foram decorrentes da etapa de intervenção com as professoras, visto que as intervenções ocorreram em momentos diferentes, e a mudança no comportamento ocorreu somente depois que a intervenção foi introduzida. Nessa perspectiva, demonstrou-se a eficácia do procedimento com as mudanças nas reações após a introdução da intervenção (Cozby, 2006).

\section{Discussão}

O ambiente escolar é diretamente responsável pelo desenvolvimento integral da criança, pois abrange um siste- ma complexo de relacionamentos interpessoais e intergrupais (Del Prette \& Del Prette, 2005a), e os adultos desse ambiente, mais especificamente os professores, funcionam enquanto agentes de controle (Skinner, 1953/2000). Nesse sentido, o estudo baseou-se na suposição de que os professores servem de modelos e funcionam como ambiente social relevante para a emissão de comportamentos de seus alunos. Diante disso, esta pesquisa buscou oferecer aos professores participantes condições para descrever comportamentos de acordo com conceitos éticos, sociais e de cidadania compatíveis com o desenvolvimento do sentido de justiça social e verificou os efeitos do ensino a partir das avaliações de desempenhos dos alunos e dos relatos dos professores, antes e depois da etapa de intervenção. Com base nos resultados obtidos, pode-se dizer que tal objetivo foi atingido por parcela significativa dos participantes.

Os resultados da avaliação anterior ao procedimento de intervenção demonstraram que as crianças possuíam certo repertório básico de respostas socialmente habilidosas. Tais resultados sugerem que essas habilidades já vêm estabelecidas do ambiente doméstico e familiar relacionados a cada criança. Todavia, mesmo nos casos em que os participantes que já apresentavam bom nível dessas habi- 
lidades, os resultados gerais indicaram uma melhora nos escores de repertório socialmente habilidosos. Foram incrementadas reações habilidosas como: "expressar sentimentos positivos, dar e receber feedback positivo, agradecer; expressar desagrado e pedir mudança de comportamento; analisar problemas e tomar decisões".

Esses dados gerais sugerem uma dimensão cultural do alcance desta proposta, pois a intervenção sobre o comportamento do professor promoveu melhoras nos comportamentos socialmente habilidosos de seus alunos e, uma vez que tais comportamentos já estavam presentes (aferidos pela avaliação pré-intervenção), supõe-se que comportamentos adquiridos em ambiente escolar possam ser mantidos em ambiente doméstico pelo fato dos pais ou cuidadores possivelmente apresentarem ações que reforçam ou mantêm tais comportamentos. Nesse sentido, Glenn e Malagodi (1991), ao analisarem a unidade conceitual das metacontingências enquanto instrumento de avaliação e intervenção no contexto de comportamentos sociais complexos, explicitam que "quando relações comportamentais que definem parte do conteúdo do repertório de um organismo são replicados no repertório de outras pessoas, em um sistema sociocultural, o comportamento replicado é chamado de prática cultural" (p. 5).

A hipótese da presente pesquisa foi a de que, ao se intervir com professores, poderia haver um impacto sobre o comportamento das crianças, uma vez que as professoras são responsáveis pelo planejamento das condições de ensino em sala de aula (Zanotto, 2000). É nesse sentido que o procedimento de intervenção desta pesquisa consistiu na apresentação de um rol de comportamentos socialmente habilidosos para o manejo de situações conflitantes em sala de aula. Ofereceu também condições para que as professoras discriminassem o ambiente comportamental oferecido pelos seus alunos e propusesse alternativas de manejo a partir das ações denominadas de socialmente habilidosas e observasse os efeitos dessas ações sobre o seu relacionamento com os alunos e sobre a relação dos alunos entre si. As tarefas de casa, realizadas pelas professoras, visou à eficiência da intervenção e a sua generalização mediante a experimentação de contingências reais das habilidades treinadas. A participação da pesquisadora nos momentos da aula fornecendo modelos à professora sobre como mediar as relações de acordo com o as habilidades discutidas nos encontros, possibilitou, também, elaborar e implantar a intervenção de forma mais próxima às necessidades identificadas no ambiente escolar, adequando-a enquanto estava sendo realizada e caracterizando-a como um produto dessas necessidades e não como uma finalidade em si mesma.

As professoras mostraram um aumento na utilização de habilidades como expressão de sentimento positivo, feedback positivo e solicitação de mudança de comportamento, em detrimento de esquemas negativos e de punição. Relataram satisfação quanto ao próprio desempenho, maior manejo no trato com os alunos e menor incidência de problemas de comportamento. Quanto mais as professoras apresentarem adequadamente tais habilidades, mais modelos estarão dando aos seus alunos, o que, possivelmente, pode garantir a manutenção desses comportamentos.

As crianças melhoraram significativamente no escore total nas avaliações pós-intervenção. Os escores obtidos pelos alunos da sala 1 no pós-teste foram significativamente melhores do que no pré-teste, o que indica que a execução de comportamentos socialmente habilidosos pelo professor facilita o desenvolvimento de repertórios pró-éticos e pró-sociais de seus alunos. As mudanças na sala 2 também ocorreram de maneira mais substancial após a intervenção nessa sala, o que sugere que também estão relacionadas ao conjunto de instruções que o professor recebeu. Esses resultados apontam a diminuição de frequência de problemas de comportamento e aumento de frequência de comportamentos socialmente habilidosos.

\section{Conclusão}

Os resultados apresentados sugerem que a intervenção com as professoras foi efetiva na promoção de comportamentos socialmente habilidosos e na redução de comportamentos agressivos das crianças. As professoras ampliaram as oportunidades de interação em sala de aula, o que propiciou maior variabilidade de modelos condizentes com a instalação e manutenção de comportamentos pró-éticos e pró-sociais indispensáveis para a socialização e autonomia dos alunos. Para avaliação de seguimento acerca da efetividade do procedimento deste estudo, desenvolveu-se nova pesquisa, em continuidade a esta (Rocha \& Carrara, 2008), que avaliou positivamente que os comportamentos socialmente habilidosos se mantiveram no repertório dos alunos. Os participantes foram os mesmos e foram avaliados com o mesmo instrumento (IMHSC - Del Prette \& Del Prette, 2005b). Análise preliminar de resultados sugere consolidação e permanência do repertório comportamental instalado.

\section{Referências}

Abid, J. A. D. (2001). Teoria moral de Skinner e Desenvolvimento Humano. Psicologia: reflexão e crítica, 14(1), 107-117.

Bobbio, N. (1992). A era dos direitos. Rio de Janeiro: Editora Campus.

Brasil. (1998). Ministério da Educação e do Desporto. Secretaria de Educação Fundamental. RCNEI - Referencial Curricular Nacional para a Educação Infantil (Vol. 2 - Formação Pessoal e Social). Brasília: MEC/SEF.

Carrara, K. (1995). A Psicologia e a construção da cidadania. Psicologia: ciência e profissão, 16, 12-17.

Carrara, K., Bolsono-Silva, A. T, Almeida-Verdu, A. C. M, Melchiori, L. E, Leite, L. P, \& Calais, S. L. (2004). Ensino fundamental, aprendizagem e desenvolvimento: um aporte da psicologia à construção da cidadania na escola. Pesquisa FAPESP concluída (2004/14157-0). 
Cozby, P. C. (2006). Métodos de pesquisa em ciências do comportamento. São Paulo: Atlas.

Del Prette, Z. A. P., \& Del Prette, A. (2001a). Habilidades sociais: biologia evolucionária, sociedade e cultura. Em H. J. Guilhardi, M. B. B. P. Madi, P. P. Queiroz \& M. C. Scoz (Orgs.), Sobre o comportamento e cognição: expondo a variabilidade (vol. 8, pp. 65-75). Santo André, SP: ESETec Editores Associados.

Del Prette, Z. A. P., \& Del Prette, A. (2001b). Psicologia das relações interpessoais. Vivências para o trabalho em grupo. Petrópolis, RJ: Vozes.

Del Prette, Z. A. P., \& Del Prette, A. (2005a). Psicologia das habilidades sociais na infância: teoria e prática. Petrópolis, Vozes.

Del Prette, Z. A. P., \& Del Prette, A. (2005b). Sistema Multimídia de Habilidades Sociais para Crianças (SMHSC). São Paulo: Casa do Psicólogo.

Dittrich, A., \& Abib, J. A. D. (2004). O sistema ético skinneriano e consequências para a prática dos analistas do comportamento. Psicologia: reflexão e crítica, 17(3), 427-433.

Falcone, E. O. (1998). Avaliação de um programa de treinamento de empatia com universitários. Tese de Doutorado, Instituto de Psicologia da Universidade de São Paulo, São Paulo.
Glenn, S. S., \& Malagodi, E. F. (1991). Process and content in behavioral and cultural phenomena. Behavior and Social Issues, 1,1-14.

Oliveira, R. J. (2001) Ética na escola: (re)acendendo uma polêmica. Educação \& Sociedade, 22(76), 212-231.

Robinson, J. (2001). Modelo de enseñanza em la Comunidad Alternativa Los Horcones: Conductismo Radical como filosofia de la educación. Em K. Carrara, Educação, Universidade e Pesquisa: paradigmas do conhecimento no final do milênio (pp. 129-142). Marília, SP: Unesp Marília Publicações.

Rocha, J. F., \& Carrara, K. (2008). Formação ética e suas implicações para a construção da cidadania: um estudo a partir da interação professor-aluno. Pesquisa PIBIC/CNPq concluída (103774/2008-4).

Skinner, B. F. (2000). Ciência e comportamento humano. São Paulo: Martins Fontes. (Trabalho original publicado em 1953)

Skinner, B. F. (1971). Beyond freedom and dignity. New York: Alfred A. Knopf.

Zanotto, M. L. B. (2000). Formação de professores: a contribuição da análise do comportamento. São Paulo: Educ.

\section{Sobre os autores}

Juliana Ferreira da Rocha (ju@fc.unesp.br)

Bolsista de Iniciação Científica PIBIC/CNPq, proc. n. 106478/2007-9 e Graduanda do curso de Formação de Psicólogos - Universidade Estadual Paulista - UNESP - Campus de Bauru, SP.

Kester Carrara (kestercarrara@pq.cnpq.br)

Docente do Programa de Pós-graduação em Psicologia do Desenvolvimento e Aprendizagem/Departamento de Psicologia - UNESP, Campus de Bauru, SP. Bolsista de Produtividade em Pesquisa do CNPq.

\section{Endereço para correspondência}

Juliana Ferreira da Rocha - Rua Ouvidor Peleja, 621, Vila Mariana, 04128-001. São Paulo, SP. E-mail: .

Kester Carrara - Universidade Estadual Paulista, Faculdade de Ciências, Departamento de Psicologia. Avenida Engenheiro Luiz Edmundo Carrijo Coube, 14-01, 17033-360. Bauru, SP.

\section{Endereço para correspondência com o editor}

Kester Carrara - Universidade Estadual Paulista, Faculdade de Ciências, Departamento de Psicologia. Avenida Engenheiro Luiz Edmundo Carrijo Coube, 14-01, 17033-360. Bauru, SP. Fone: (14) 3103-6087, Fax: (14) 3103-6071.

Os autores são gratos ao Programa Nacional de Bolsas de Iniciação Científica (PIBIC/CNPq), pela bolsa concedida para a realização do projeto de pesquisa que originou o presente artigo e às Professoras Dras. Ana Claudia Moreira Almeida-Verdu e Alessandra Turini Bolsoni-Silva pela leitura do manuscrito e sugestões. 